\title{
GRAFISMO CORPORAL E SABER TRADICIONAL TENETEHAR TEMBÉ DE GUAMÁ
}

\author{
José Agnaldo Pinheiro Pereira ${ }^{1}$ \\ José Guilherme dos Santos Fernandes ${ }^{2}$ \\ Recebido em: 10/08/2017 \\ Aprovado em: 04/09/2017
}

As expressões culturais de diferentes etnias indígenas no estado do Pará, a exemplo do grafismo corporal, em geral pouco estudadas, configuram um conjunto interligado de conhecimentos, que

(...) são saberes e práticas que não poderiam, logicamente, ser nem deles, nem de outros grupos. Não só porque são produto das redes de troca entre humanos e sobrenaturais, como porque são gerados e apenas expressados no âmbito desse sistema de trocas, entre pessoas, entre grupos, entre humanos e não humanos (...) GALLOIS (2007 p. 97-98).

Desse modo, o grafismo corporal enquanto traço manifesto da cultura material e imaterial desses povos está relacionado à identidade étnica.

Após décadas de negação e alienação de seus direitos tradicionais e vivendo sob o regime de tutela de órgãos oficiais como o Serviço de Proteção ao Índio (SPI) e Fundação Nacional do Índio (FUNAI), os Tenetehar de Guamá reorganizaram-se junto aos parentes de Gurupi, na luta pelo território e fortalecimento da cultura tradicional, o que levou ao ressurgimento das pinturas corporais no final da década de 1980 e início dos anos 1990.

A reintrodução do grafismo corporal como traço cultural da identidade de autoafirmação étnica deve ser avaliado também como uma estratégia política simbólica de diferenciação, pautada na ideia de ancestralidade que abrangeu diferentes contextos socioculturais dos Tembé de Guamá.

A referência cultural para o uso das pinturas corporais no subgrupo tupi Tembé Tenetehar de Guamá, entre os anos de 1985 e 1993, foram as memórias, os saberes e as práticas dos parentes de Gurupi, que passaram a ensinar além da brincadeira do Kaê-kaê (eheehe) e de algumas cantorias, o preparo e o uso do jenipapo e do urucum na elaboração de padrões tradicionais das pinturas corporais, mais especificamente as pinturas da cuia, da meia-

\footnotetext{
${ }^{1}$ Mestrando do Programa de Pós-Graduação em Linguagens e Saberes da Amazônia - UFPA/Campus Bragança (PPLSA). Email: agnusgrunge@gmail.com

${ }^{2}$ Pós-Doutor. Professor dos Programas de Pós-Graduação Linguagens e Saberes na Amazônia- UFPA/Campus Bragança (PPLSA) e Estudos Antrópicos da Amazônia -UFPA/Campus de Castanhal (PPGEAA). E-mail: mojuim@uol.com.br
} 
lua e da onça pintada. Paralelamente outros modelos e padrões de grafismos corporais de outras etnias foram assimilados.

Abrangendo diferentes contextos socioculturais em sua forma de expressão e manifestação, como em rituais a exemplo da Wyra'whaw, o uso da pintura corporal entre os Tenetehar Tembé de Guamá assume importância na medida em que envolve conhecimento tradicional, valor e sentido de identidade repassados oralmente entre parentes de Guamá e de Gurupi, e que está presente na diversidade simbólica corporeavisual e espacial, bem como no significado que traduz enquanto elemento natural que ajuda no desenvolvimento das crianças e na mediação entre o mundo real e o sobrenatural.

O uso corporal do jenipapo, do urucum e de outras essências naturais pelos Tembé de Guamá no ritual de agregação da Wyra’w haw, está relacionado a uma forma de comunhão cosmológica que celebra a boa saúde física, mental e espiritual dos iniciados na passagem para a vida adulta. Segundo We Wer Tembé ${ }^{3}$, o uso do jenipapo no corpo atrai karowara (espíritos) porque entre alguns pajés Tenetehar é visto como uma dádiva recebida esses seres encantados ou donos da natureza, e se manifestam em pessoas de "peito aberto" enquanto espíritos de animais como a borboleta e a arara, ou "fechados" pela mãe d'água.

We Wer Tembé afirmou que os karowara também são espíritos de parentes Tenetehar, que já se foram desta vida, mas que retornam durante a "Festa do Moqueado" e são atraídos pelas cantorias e pelo jenipapo. A exemplo do que ocorre com o uso do jenipapo entre os índios Waiãpi, “(...) a pintura marca a separação entre os vivos e os mortos, que deixam de usar o jenipapo e de pertencer ao mundo social (...)" VIDAL (1992, p.131).

A partir de 2003 foi introduzido entre os Tembé de Guamá, o ritual da Wyra’w haw ${ }^{4}$ (Festa dos espíritos), também conhecida como "Festa da Menina Moça" ou "Festa do Moqueado". Nesse ritual, que envolve três fases, a "tocaia", o "Mingau da Menina Moça" e a "Festa do Moqueado", o jenipapo assume também a função de purague (remédio) usado nos corpos das meninas simbolizando a lua nova, a onça jaguatirica e a guariba ${ }^{5}$, e dos meninos, também como referência à guariba e à lua nova.

\footnotetext{
${ }^{3}$ Pajé e cantador em rituais da Wyra'w haw, e grande conhecedor das tradições Tenetehara.

${ }^{4}$ É uma expressão na língua Tembé, que segundo o professor Txina'i Tembé se relaciona a um conjunto de significados, dentre os quais, Wyra - espírito de pássaro grande, e haw - passagem para o outro lado; lugar, local.

${ }^{5}$ Existe divergência entre os Tembé de Guamá e de Gurupi quanto à simbologia da pintura usada em todo o corpo da menina moça, e nas mãos, pés e parte inferior do rosto do menino, na última fase da Wyra'w haw. Entre vários Tembé de Guamá, é tida como do animal guariba; para We Wer Tembé, ela se relaciona ao desenvolvimento dos iniciados. Levantamos a hipótese de que houve uma renomeação dessa pintura corporal, assim como de outras, pelos Tembé de Guamá.
} 
As transformações efetuadas no corpo pelas diferentes modalidades de revestimento - pintura, escarificação ou odor - têm por objetivo alterar a posição do indivíduo em face de seus vizinhos e, sobretudo, em face do mundo sobrenatural. Em todos os casos, visam modificar a distância - aproximando ou separando - entre o homem e o mundo dos outros, sejam eles indivíduos rivais ou entidades sobrenaturais... (VIDAL, 1992, p. 227).

Em maio de 2012, participamos do mingau de três jovens iniciadas na aldeia Ytaputyr, onde foi possível fazer uma entrevista oral com Paxik Tembé, pajé e sábio conhecedor das tradições Tembé de Gurupí. Indagamos sobre o significado das pinturas que as jovens usavam nos membros superiores e inferiores, bem como nas costas, peito e barriga. Informou que se tratava da pintura da meia-lua ou lua nova, e apontando para o céu falou que as meninas estavam em fase de crescimento assim como a lua nova. Quanto à pintura usada na face da menina moça, Paxik Tembé informou ser a da onça pintada, animal presente nas matas do Gurupi, e considerado encantado para os Tenetehar Tembé e Guajajara. Paxik Tembé afirmou que foram as onças quem ensinaram os Tenetehar a fazerem a "Festa do Moqueado".

A "Festa do Moqueado" entre os Tembé de Guamá, é realizada atualmente nas aldeias Ytaputyr e Sede, e ocorre durante uma semana na estação do verão entre junho e dezembro e envolve jovens Tembé de Guamá e de Gurupi.

Após o termino da Wyra'w haw, os meninos e meninas iniciados não podem tomar banho em rio e igarapé desacompanhados, nem sair à noite ou adentrar locais de matas sozinhos enquanto o jenipapo ainda estiver no corpo.

Este ensaio etnofotográfico em sequência narrativa fotográfica de jovens Tembé Tenetehar em ritual de passagem compreende duas fases da Wyra'w haw: o "Mingau da Menina Moça" e a "Festa do Moqueado" registradas nos anos de 2010 e 2012, na aldeia Ytaputyr, Terra Indígena Alto Rio Guamá, e coloca em evidência a importância da pintura corporal enquanto traço da identidade cultural desta etnia.

\section{REFERÊNCIAS}

GALLOIS, Dominique Tilkin. Materializando saberes imateriais: experiências indígenas na Amazônia Oriental. Revista de Estudos e Pesquisas, FUNAI, Brasília, v 4, n 2. 2007.

VIDAL, Lux. Grafismo Indígena: estudos de antropologia estética. São Paulo: Studio Nobel: Editora da Universidade de São Paulo: FAPESP, 1992. 

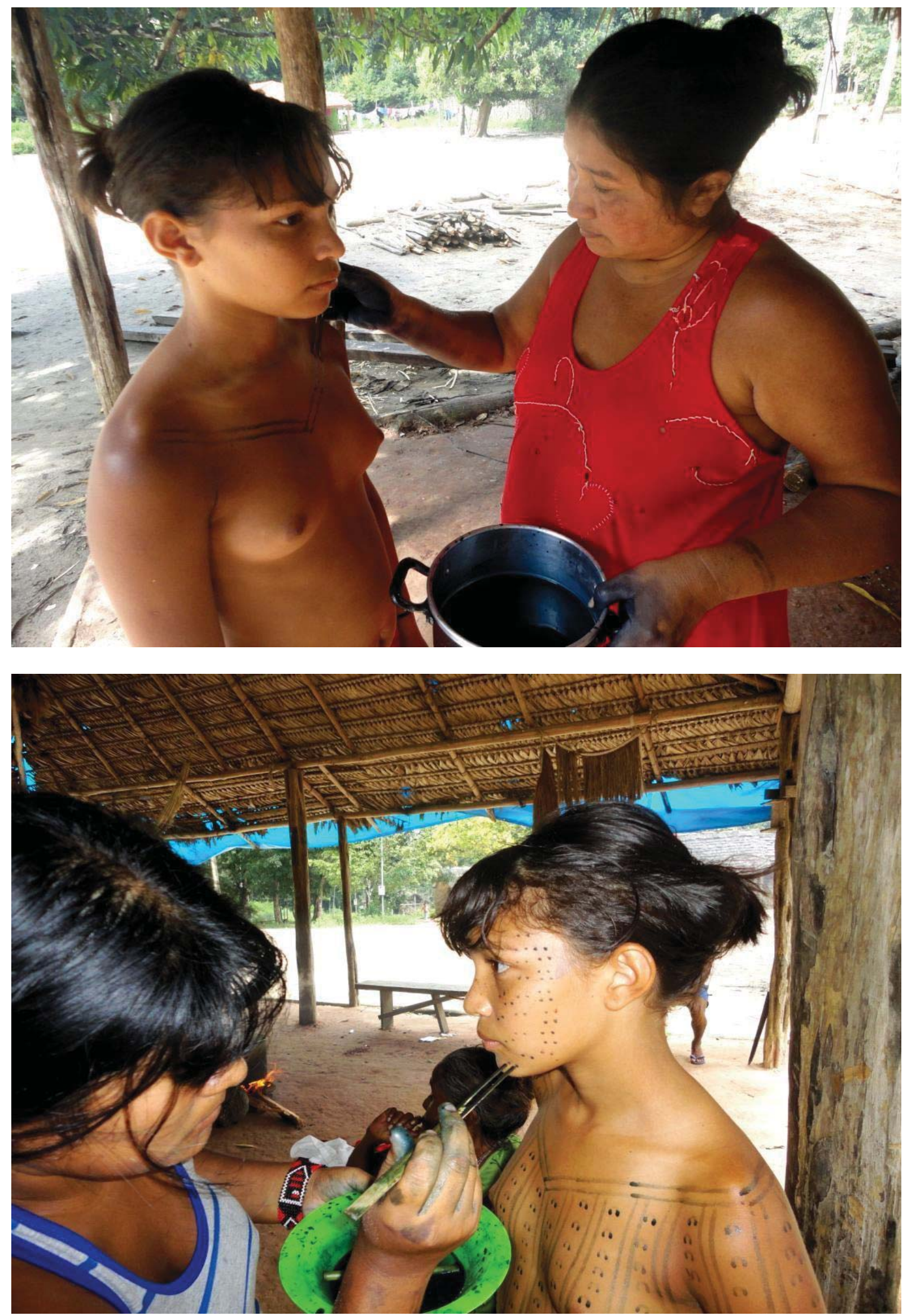

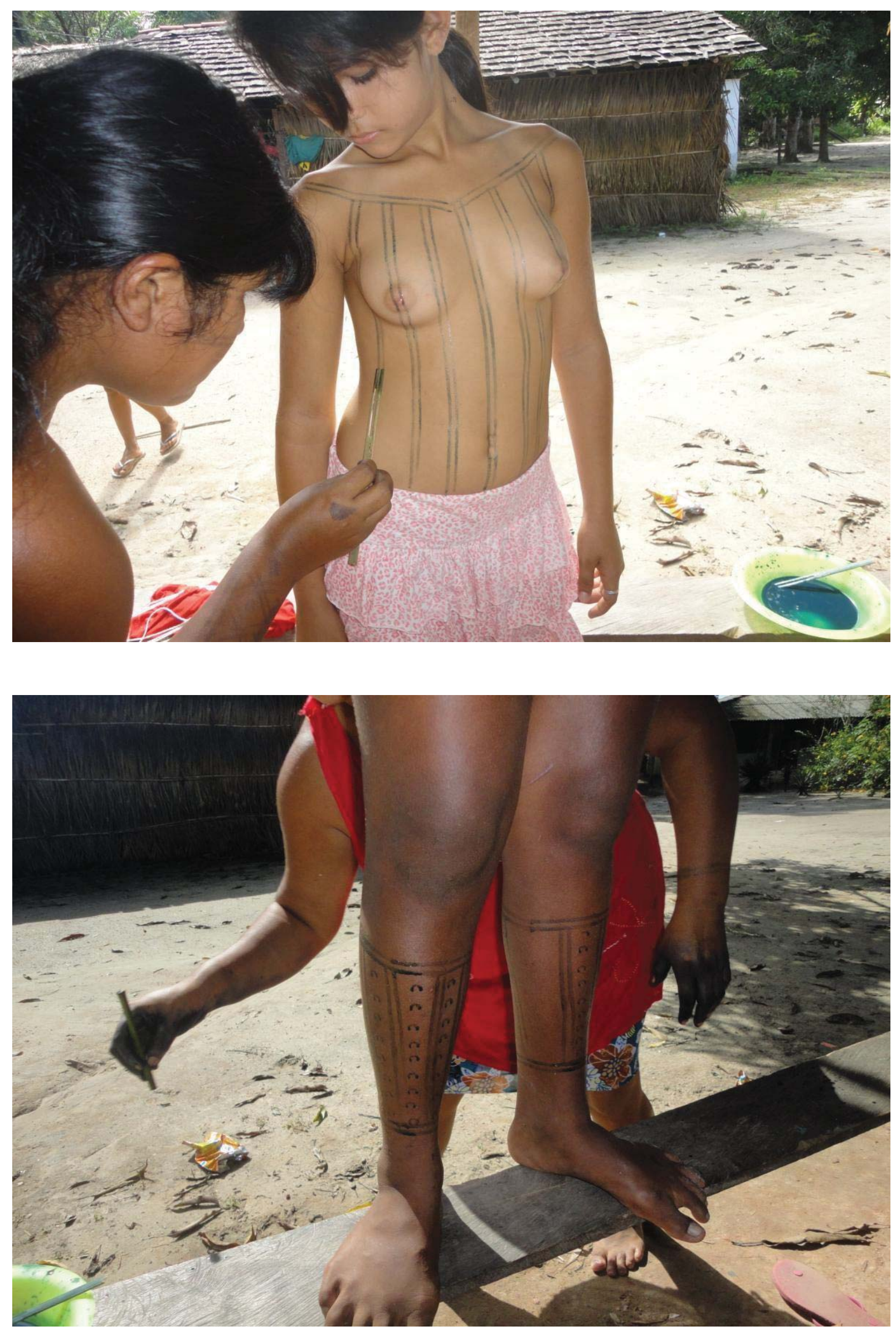

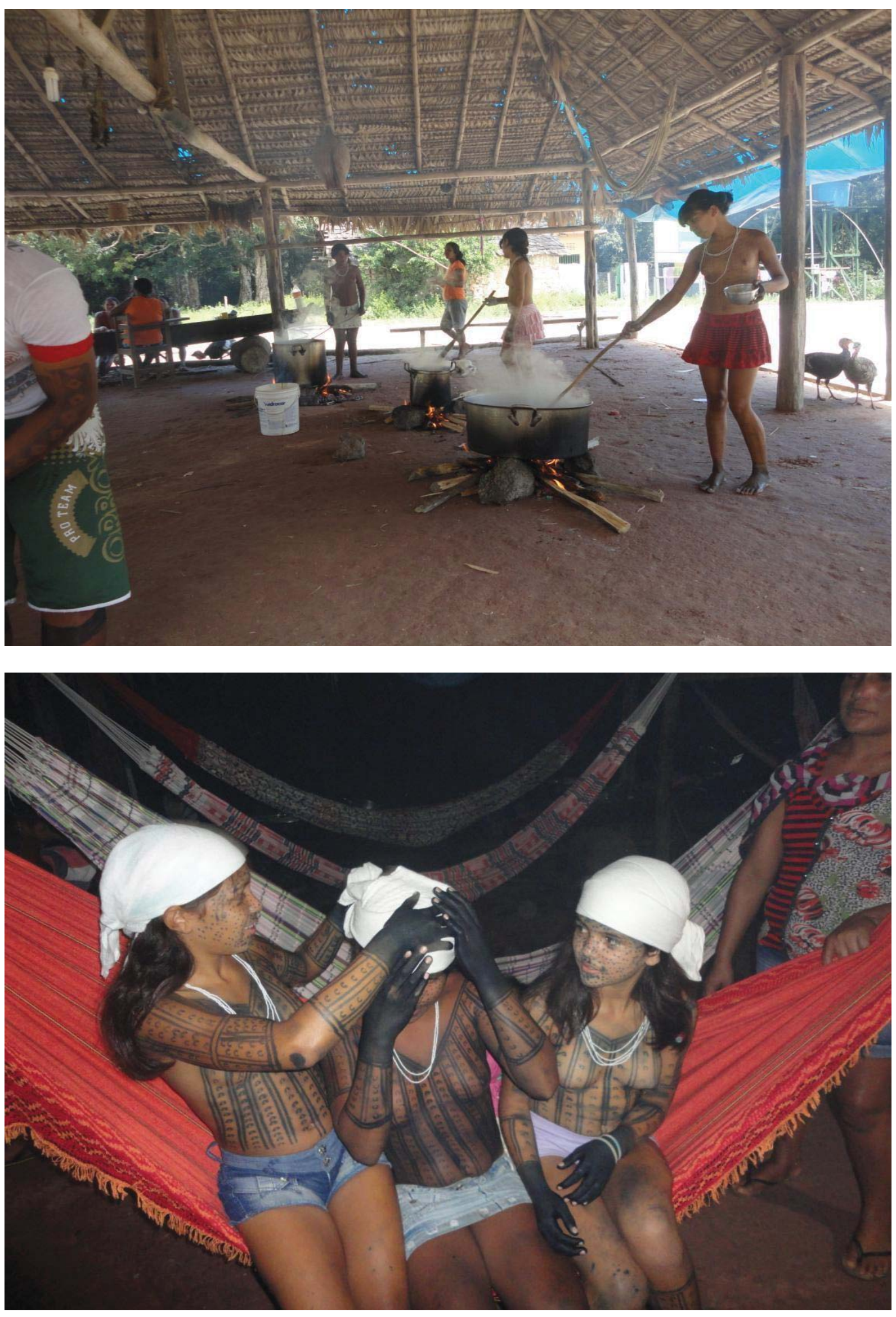

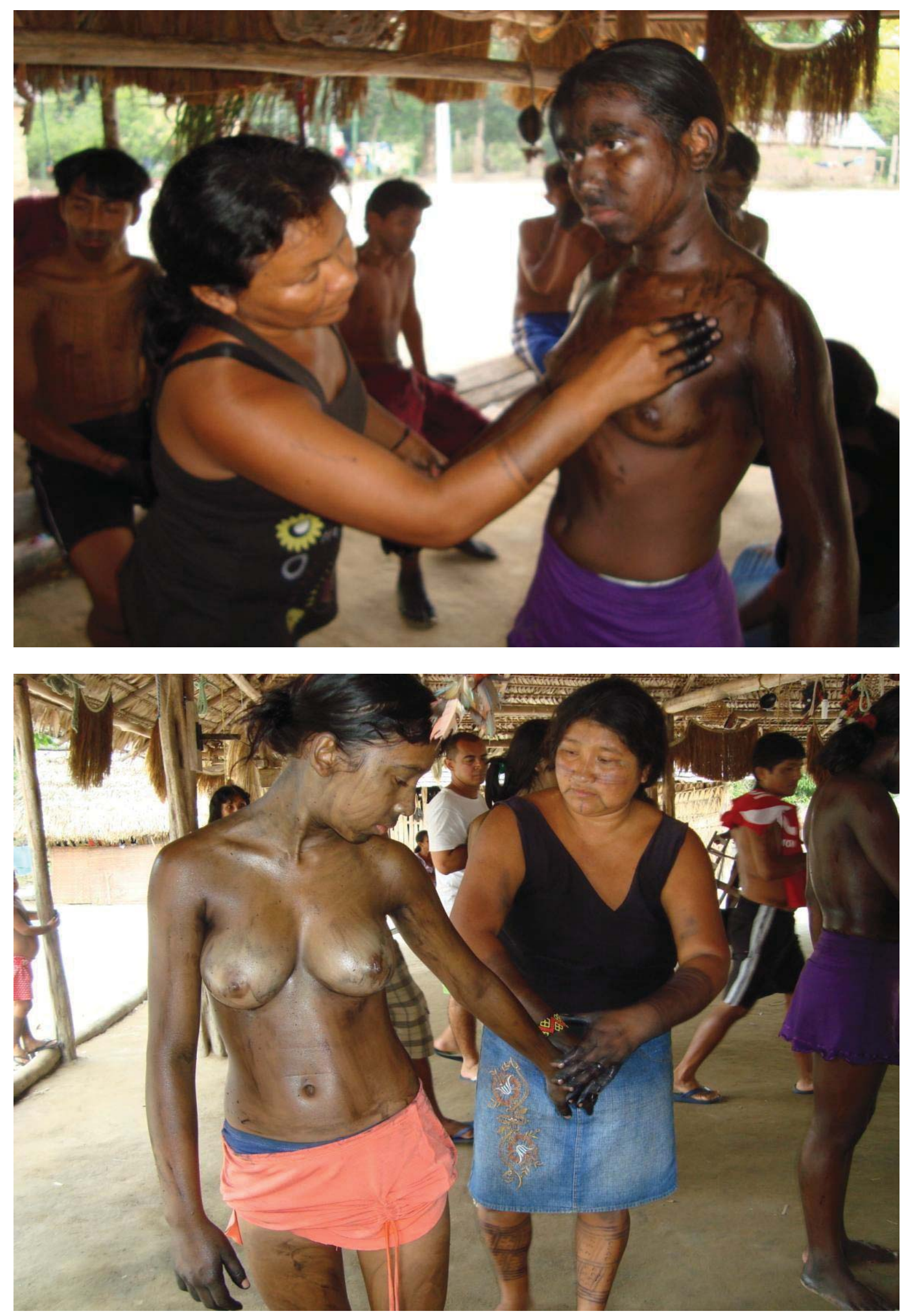

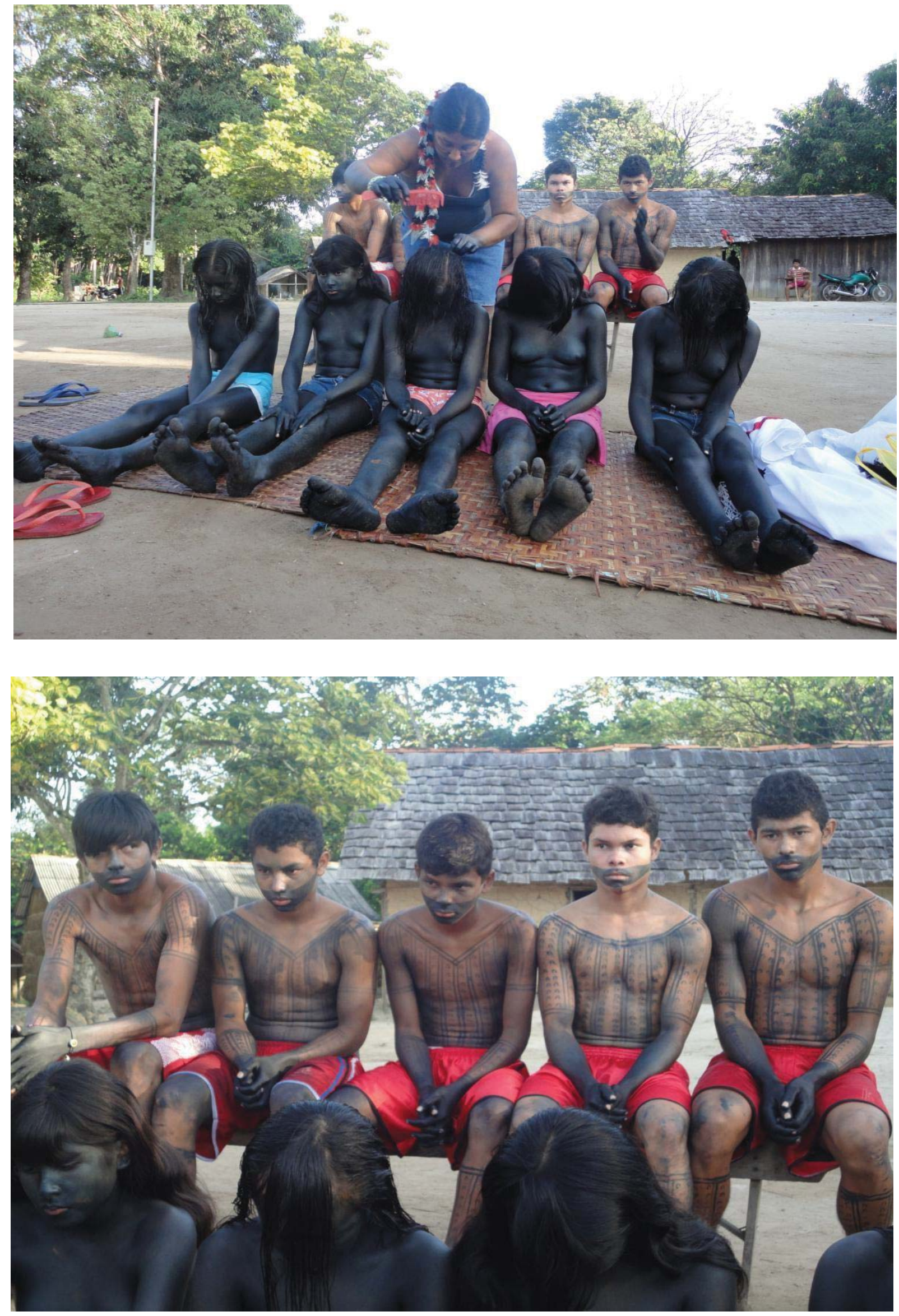

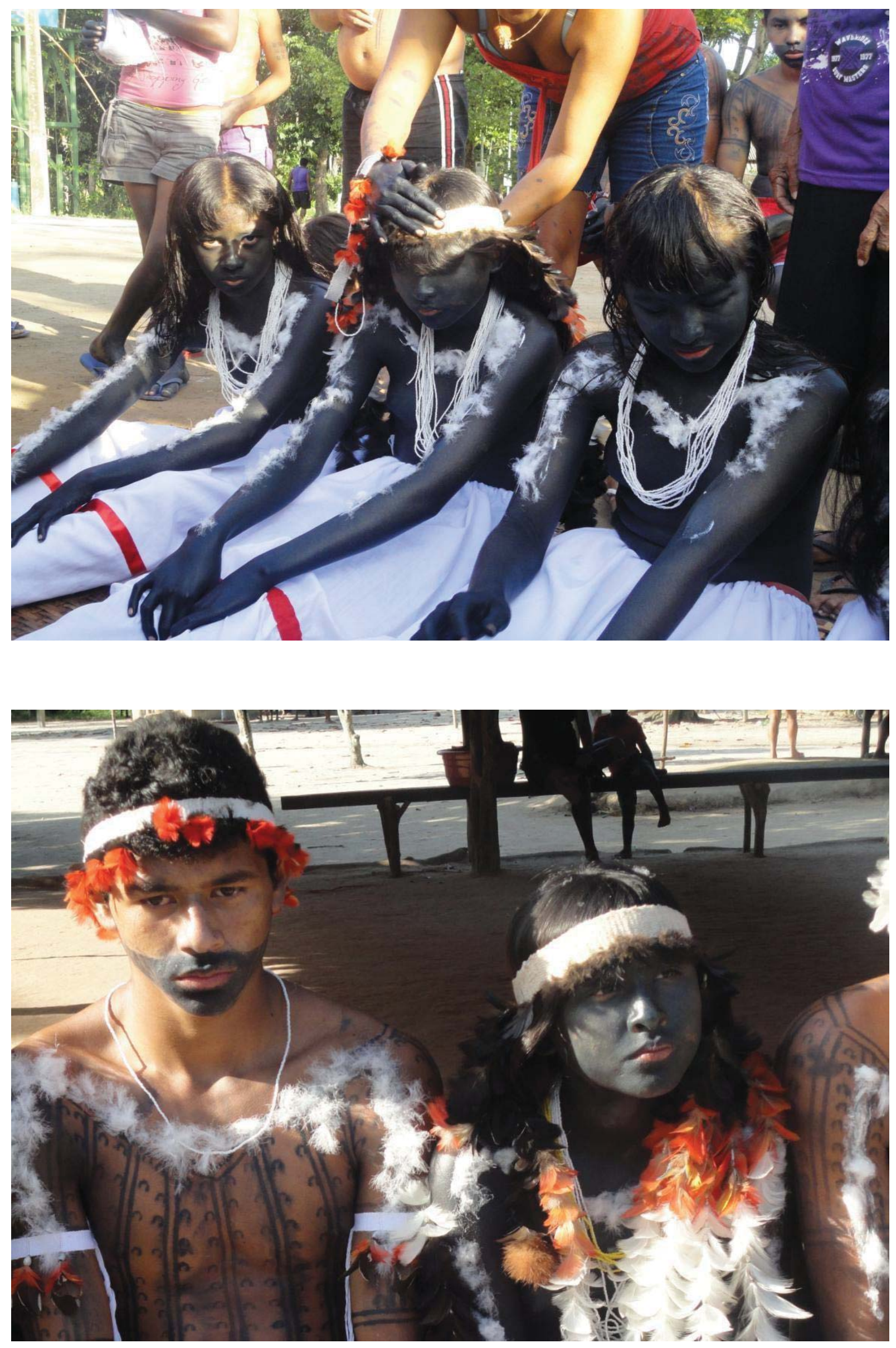